\title{
Negotiation Support and Risk Reduction in Collaborative Networks
}

\author{
Ana Inês Oliveira ${ }^{1}$ and Luis M. Camarinha-Matos ${ }^{1,2}$ \\ ${ }^{1}$ CTS, Uninova, Departamento de Engenharia Electrotécnica, Faculdade de Ciências e \\ Tecnologia, FCT, Universidade Nova de Lisboa, 2829-516 Caparica, Portugal \\ ${ }^{2}$ Faculdade de Ciências e Tecnologia, Universidade Nova de Lisboa, Campus da Caparica, \\ Quinta da Torre, 2829-516 Monte Caparica, Portugal \\ \{aio, cam\}@uninova.pt
}

\begin{abstract}
In face of the current economic turbulence, companies face new challenges. In order to respond to new business opportunities, it is crucial that companies attain strategic alliances so that they can obtain or maintain market competiveness. The formation of alliances and partnerships for collaborative problem solving is of extreme importance, being therefore essential to understand their structures and requirements. To overcome a number of difficulties that may appear in the formation of such alliances, it is necessary to properly model the elements that constitute the alliance agreements through a suitable negotiation support environment that besides the basic functionalities of data storage and alerts can also conduct the entire negotiation process making it traceable. In this context, this paper presents the main requirements of an electronic negotiation support environment in a collaborative network, identifies the main risk sources and drivers in collaborations, and analyses how a negotiation support system can help in reducing the potential risk in collaboration.
\end{abstract}

Keywords: collaborative networks, negotiation support environment, risks, agreement.

\section{$1 \quad$ Introduction}

In today's unstable and highly competitive business environments companies and organizations have to shift their modus operandi if they want to obtain or maintain market competiveness. It is therefore essential to move to a new business paradigm where the creation of strategic alliances is vital[1,2].Past "traditional" enterprises are increasingly replaced by new collaboration structures of enterprises, forming temporary networks of independent companies that share skills, costs and access to each other's market[3].In this context, the possibility of rapidly forming a consortium to respond to a business or collaboration opportunity gives companies an expression of agility and survival mechanisms in face of this market turbulence. Moreover, the topic of collaborative networks (CNs) appears as significantly promising because if enterprises or organizations share a common interoperable infrastructure, common operating principles, common cooperation agreements, and a base of trust among 
them, then their ability to rapidly form virtual organizations(VOs) is increased [4]. Nevertheless, this kind of business formation is not without risks, so besides the important and classical task of selecting the adequate partners with the most suitable competencies to form a consortium able to respond to the requirements of the business or collaboration opportunity $(\mathrm{BO} / \mathrm{CO})$, it is also of extreme importance to consider the potential risks in collaboration. If there is a robust and reliable negotiation environment that supports the potential VO partners in achieving agreements during the $\mathrm{VO}$ creation process considering the involved collaboration risks, then that may lead to a reduction of risks and amount of time spent in this process. These VO agreements will be the basis for the governing principles of the VO during its operation phase[5].Considering this background and a virtual organization breeding environment (VBE) [6] context, that supports and fosters the creation of dynamic VOs, the main research question that emerges is:

How can an electronic negotiation support environment increase the agility in the creation process of successful dynamic virtual organizations?

One important motivation for this work is that by contextualizing the VO creation process in the VO breeding environment (VBE), making use of all its infrastructures and functionalities, the process may become more agile in terms of time. Furthermore, identifying and characterizing the involved potential collaboration risks can also make the process more agile in terms of adaptation to unexpected events and thus reducing the risks in collaboration. Moreover, managing risks in VOs is a rather underexplored and unstructured scientific area [3].

\section{Technological Innovation for the Internet of Things}

The Internet of Things (IoT) is a novel paradigm that is rapidly gaining ground in the scenario of modern wireless telecommunications[7]. This paradigm is based on the concept of pervasive presence of a variety of things or objects (such as RFID tags, sensors, actuators, mobile phones, etc.) which are able to interact with each other and even cooperate to reach common goals[8]. As a result, the IoT causes a natural impact on the behavior of its users, either in everyday-life or business aspects.

In the context of a negotiation process towards the creation of a VO, it is of extreme importance that the potential partners can have quick access to relevant information that is acquired through devices or other objects of their business environment so that it can contribute to boost the VO creation process. For that reason, if the potential partners of the VO have access to information, independently of the geographical place where they are (through different devices, e.g. smart phones), and on top of that have access to the required information of their infrastructure and related devices in real time, then the negotiation of the VO creation process it could become more agile in terms of time, and therefore the IoT appears as a suitable paradigm.

On the other hand, in collaborative networks, while the IoT can help to overcome some technical problems, in terms of finding accurate information and providing anywhere and anytime access, there are some business aspects that are still open issues. Therefore, a negotiation support environment that deals with this information can also contribute to elaborate on new business models related to the IoT [9]. 


\section{$3 \quad$ Related Literature}

Being the main topic of this work a negotiation support environment to assist organizations to increase the agility of a VO creation process, it is then essential to mention a brief summary of related literature that has directly influenced the current work. More detailed review of related literature can be found in $[5,10,11]$.

VOs and Their Related Environments. Collaborative networks is a scientific discipline that covers the study of networks consisting of a variety of entities that are largely autonomous, geographically distributed and heterogeneous, and that collaborate to better achieve common or compatible goals, and whose interactions are supported by computer network [4, 12]. The Virtual Organization paradigm constitutes one of the first manifestations of the collaborative networks. Being the concept developed and applied in several domains and areas, many contributions for the characterization and modeling of the paradigm can be found in the literature, as exemplified by[1, 2, 4, 13]. The main idea behind this concept is basically of a temporary consortium of enterprises and/or organizations, geographically dispersed, that strategically join their competencies to rapidly respond to a business or collaboration opportunity. Previous works have established some reasons for companies or organizations to establish cooperative/collaborative networks, such as [14]: flexibility, capacity, speed, skills and competences, etc. The main outcome here is always the risk-sharing, but also, the sharing of gains either in terms of profit or in terms of market information. Nevertheless, in face of a new business opportunity, if companies can take advantage of a common interoperable infrastructure, common operating rules, common cooperation agreement, and a base trust level among the organizations, then they become more ready and prepared to collaborate. Therefore, an approach is to consider that dynamic VOs are mostly created in the context of a VO Breeding Environment (VBE)[4, 6].

Risks in Collaborations. Risk is an ambiguous concept, thus there are many definitions of risk depending on the specific application and on the situational context[15]. One of the most common meanings for risk is a threat or danger and often implies the probability of a negative outcome. Harland, Brenchley \& Walker [16] have done an exhaustive review of definitions and classifications of types of risk and defined risk (R) as the product of the probability (P) of a loss (loss) and the significance or impact (I) of the loss, related to an event $\mathrm{n}(\mathrm{n}): \mathrm{Rn}=\mathrm{P}($ loss $) \mathrm{n} \times \mathrm{I}(\mathrm{loss}) \mathrm{n}$. Other authors claim that risk, per se, has neither a positive nor a negative value and is perhaps more related to uncertainty, where eventualities can be either beneficial or adverse[3].Considering the VO life-cycle, there are of course some risks that traditional risk management does not deal with, in particular when considering the sharing of skills, costs and access to each other's markets. Also, risks may change from project to project or opportunity to opportunity. Therefore, new challenges in how to manage VO risks are enforced.

Negotiation and Contracting. Negotiation is an iterative communication and decisionmaking process between two or more parties who seek a consensus decision and cannot apply unilateral actions to achieve their objectives [17, 18].As a negotiation processes involve a transversal, multi- and inter-disciplinary approach, it is necessary to have a holistic view of the problem, making use of multiple methodologies and paying attention 
to the practical details [19]. A negotiation process can rely on several mechanisms such as: auctions, game theory, intelligent agent mechanisms, etc. [20]. Nevertheless, such process if often conducted by human actors that in the last instance are the ones responsible for decision-making.Although some works try to insert some automation into the negotiation process $[21,22]$, this continues to be a rather difficult issue. Progress in this area during the last years has highlighted a number of important topics that need to be considered when developing processes and methodologies for negotiation, including Contract Models, Ontology, Contract Framework, Electronic Institutions, Digital Signature, etc [5].

Considering the above rich conceptual inheritance but also practical requirements attained through the interaction with existing enterprises networks, the next section describes the main requirements for an electronic negotiation support environment that considers the potential collaboration risks, and allows members of a collaborative network to conduct their negotiation towards the internal consortium agreement. As a result, the VO creation process can become more agile in terms of adaptation to unexpected events and reduce possible risks in collaboration.

\section{Research Contribution and Innovation}

Due to the continuous changes in socio-economic markets, companies and organizations have to constantly adapt themselves to survive. One option is to strategically join their competencies to rapidly respond to a business or collaboration opportunity through a goal-oriented network that is an association of individuals and/or organizations. Nevertheless, besides taking advantage of clustering themselves, companies and organizations have to find better solutions to meet the customer needs. One trend in manufacturing is to move towards highly customized products and ultimately one-of-a-kind products [23]. In this context, this trend is reflected in the term mass-customization that refers to a customer co-design process of products and services which meet the needs/choices of each individual customer with regards to the variety of different product features. Moreover, in all cases, even in the case of new product orders or co-creation teams for innovative services, the goal-oriented collaborative network can be labeled virtual organization (VO). It should be noted that different VOs, with very different time durations, can be needed during the life cycle of a complex product, such as solar energy parks, intelligent buildings, etc.

This consortium formation mainly consists in planning and scheduling the work order and selecting the appropriated partners to join the VO. But, and according to innumerous authors in literature (as mentioned in the related literature section), it is desirable that a virtual enterprise or organization is able to deal with the associated risks, vulnerability, robustness, flexibility, resilience and business continuity. Being agility, the quality or state of the organization of being able to have a quick resourceful and adaptable response, then the time and amount of resources consumed during the $\mathrm{VO}$ creation process give a good indication of the level of agility of a collaborative network. To achieve that agility, it is essential that some requirements are provided to its members, namely in terms of common infrastructures, governance models and rules etc. For that, the existence of a VO breeding environment context (VBE), enables a partial fulfillment of those requirements [6].Furthermore, due to the 
heterogeneous contexts of the VO breeding environments that usually companies or organizations belong to, it is possible to create value among VBE members if there exists an electronic negotiation support environment that contributes to boost the participation in consortia creation. Thus, the hypothesis adopted for this work is:

The process of creating dynamic virtual organizations can become more agile if an appropriate electronic negotiation wizard environment is established with the necessary soft modeling characteristics to structure and conduct the entire negotiation process, making it traceable, reducing the collaboration risks, and managing the participants' expectations. Moreover, the negotiation environment should be customizable according to different collaboration levels, either in terms of commitment or in terms of duration.

The key reason why it is important to have a consistent negotiation support environment for the formation of VOs is essentially to improve the entire process of establishing the $\mathrm{VO}$ agreement that will induce the governing rules and principles of the consortium during the operation phase and as mechanism to reduce the potential collaboration risk. Therefore, it is of extreme importance to make a comprehensive analysis of the important characteristics that such support environment shall involve.

Risk sources and drivers in collaboration. Having into account the environmental characteristics of collaboration, one topic that has considerable importance and can influence the negotiation process is the related associated risks and their prediction. For that, the current work relies on the characterization of risks and failures in collaboration, so that the negotiation model can also support risk analysis of potential risk of members' behavior during VO operation. Fundamentally it is important to consider the sources and drivers of such risks. Elementary questions arise such as: what can happen and what can be the case?; how likely is it that it will happen?; and if it does happen, what are the consequences?

Table 1. Risks in collaborative network environments

\begin{tabular}{c|ll|l}
\hline & \multicolumn{2}{c}{ Risks in Collaborative Network Environments } \\
\hline \multirow{2}{*}{$\begin{array}{c}\text { Drivers } \\
\begin{array}{c}\text { Internally-driven } \\
\text { risks }\end{array}\end{array}$} & Operational & $\begin{array}{l}\text { Human error or staff failing to } \\
\text { perform }\end{array}$ & Organizational risk \\
\cline { 2 - 4 } & Commercial & $\begin{array}{l}\text { Risk of business relationships } \\
\text { failing }\end{array}$ & Organizational/Network risks \\
\cline { 2 - 4 } & Technical & $\begin{array}{l}\text { Risk of physical assets failing } \\
\text { or being damaged }\end{array}$ & Organizational risk \\
\hline $\begin{array}{c}\text { Externally- } \\
\text { driven risks }\end{array}$ & Financial & $\begin{array}{l}\text { Uncertainty of financial } \\
\text { controls failing or succeeding }\end{array}$ & $\begin{array}{l}\text { Organizational/Network/environ } \\
\text { mental risk }\end{array}$ \\
\hline $\begin{array}{c}\text { Decision driven } \\
\text { risks }\end{array}$ & Strategic & $\begin{array}{l}\text { Related to the uncertainty of } \\
\text { plans failing or succeeding }\end{array}$ & Network risk \\
\hline
\end{tabular}

According to some authors in risk management, and collaborative environment characteristics, it is assumed that risks in collaborative environment can be categorized according to internally, externally and/or decision driven risks. Also, risks may have different sources, namely organizational, network, and/or environmental. Therefore, Table 1 includes a mapping of risks drivers and sources in collaborative network environments. 
In view of the many different VO topologies and various domains where they can be, different risks can exist. So, having into account the above risk drivers and sources in CNs, whenever there is a formation of a new VO, those risks have to be considered. Fig. 1 illustrates the case of a consortium formation with VBE members, local support entities and suppliers and customer (VO co-creation space) where there are some risks that have to be considered, as well as its drivers.

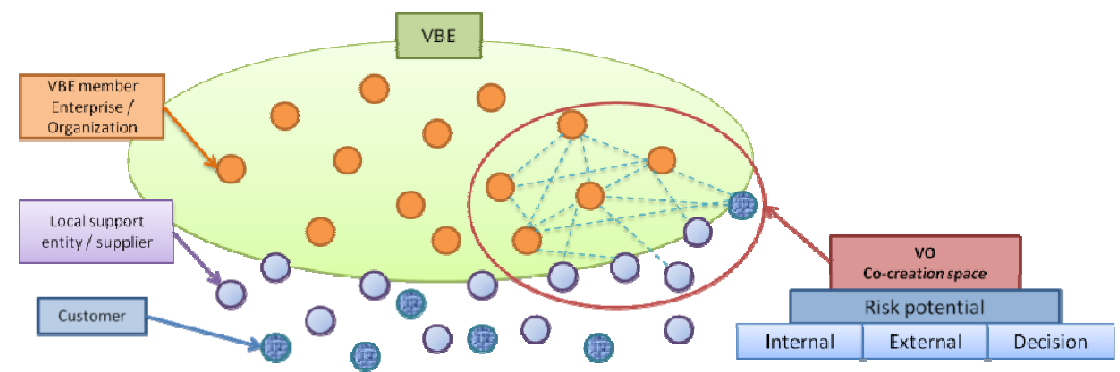

Fig. 1. Co-creation space formation

As a result, if there is a support mechanism for the consortia formation that allows the negotiation process to be conducted with mechanisms that allow risk identification and characterization, then the $\mathrm{VO}$ creation process could in fact become more agile in terms of adaptation, and failures in the operation phase also reduced.

Main requirements of a negotiation environment. To support some of the developed concepts, and through the interactions with various end-users networks various critical negotiation activities were identified:

- The contract/agreement should follow a basic set of standard templates: It is important to depart from common templates, selected for each kind of $\mathrm{BO} / \mathrm{CO}$, and extend the selected template to cope with the detailed agreement specifications using "add-on" clauses;

- Reaching agreements concerning coordination aspects;

- Reaching agreements on the detailed activities and scheduling;

- Information exchange agreement: i.e. how should information be exchanged among partners, and also which kind of information should be exchanged;

- Support for privacy of proposals, where only the involved partners have access to the information being negotiated;

- Considering the potential risks collaboration, reaching agreement concerning the sharing of risks among the involved partners; and

- Provide a mechanism for tracing the history of the negotiation.

Having into account this list, it is evident that these types of agreements require fundamentally decision making by human actors rather than fully-automated decisionmaking. Therefore, in this case, what is addressed is not a complex e-contracting process where the system is capable of automatically generate, interpret, execute, and manage a contract or agreement, but to a certain extent, a system that is capable of storing and receiving inputs into an electronic source for later interpretation and user guidance through the process. Therefore, considering the VBE context [6],the main actors involved in this process are described in Table 2 . 
Table 2. Actors in the negotiation support environment

\begin{tabular}{l|l}
\hline \multicolumn{1}{c|}{ Actors } & \multicolumn{1}{c}{ Description } \\
\hline Potential Customer & $\begin{array}{l}\text { Individual or organization that makes a new product order or innovative } \\
\text { service request. }\end{array}$ \\
\hline VO Planner & $\begin{array}{l}\text { VBE Member that in face of a new collaboration opportunity identifies the } \\
\text { necessary competences and capacities, selects an appropriate set of partners } \\
\text { (VBE Members and/or outsiders), and structures the new VO. }\end{array}$ \\
\hline $\begin{array}{l}\text { Potential VO Internal } \\
\text { VBE Partner }\end{array}$ & VBE Member that is a possible partner of the VO that is being created. \\
\hline $\begin{array}{l}\text { Potential VO Local } \\
\text { Partner }\end{array}$ & $\begin{array}{l}\text { External interested stakeholder (e.g. Local suppliers and Local Support } \\
\text { Entities), that is a possible partner of the VO that is being created. } \\
\text { Nevertheless, depending on the nature of the Potential VO Local Partner, } \\
\text { there might be different levels of involvement in the collaboration process. }\end{array}$ \\
\hline
\end{tabular}

So that the negotiation environment can be properly implemented, it is necessary that it has access to the VBE information system mainly to the VBE Members' profile and competences, as well as, access to collaboration history so that risk forecasting and partners' expectations assessment can be performed. Thus, the basic modules of the negotiation support environment are:

Table 3. Basic modules of the negotiation support environment

\begin{tabular}{|c|c|}
\hline Modules & Description \\
\hline \multirow{5}{*}{$\begin{array}{l}\text { Negotiation } \\
\text { support } \\
\text { modules }\end{array}$} & $\begin{array}{l}\text { Negotiation Template Management (NegTM). } \\
\text { Collection of contract templates and negotiation topic templates to support the VO } \\
\text { creation. In the contract construction process it should be possible to build or edit the } \\
\text { contract skeleton or template and add them to the collection. }\end{array}$ \\
\hline & $\begin{array}{l}\text { Negotiation Contract Editor (NegCE). } \\
\text { The main point of interaction with the user, allowing the initiation, conduction and } \\
\text { monitoring of the entire negotiation process in the VO creation. The main users are the } \\
\text { VO Planner and the Potential Partners (that have different authorization levels } \\
\text { depending if they belong to the VBE or are potential local partners). More details in [5]. }\end{array}$ \\
\hline & $\begin{array}{l}\text { Negotiation Virtual Negotiation Rooms (NegVNR). } \\
\text { It is the virtual space where the potential partners of the VO are invited to join in order } \\
\text { to negotiate and/or discuss the necessary topics/clauses that need an agreement. More } \\
\text { details in [5]. }\end{array}$ \\
\hline & $\begin{array}{l}\text { Negotiation Support for Agreement Establishment (NegSAE). } \\
\text { Like an e-Notary that allows clients to exchange information with warranty of } \\
\text { authenticity and validity as well as providing a safe repository for saving and requesting } \\
\text { documentation (through digital signatures and encryption techniques). }\end{array}$ \\
\hline & $\begin{array}{l}\text { Negotiation Assessment and Potential Risk Forecasting (NegAPRF). } \\
\text { Through interaction with the VBE management system it will be made an assessment of } \\
\text { potential partners' expectations towards collaboration and the forecasting of potential } \\
\text { risks of the collaboration. }\end{array}$ \\
\hline $\begin{array}{l}\text { Interaction } \\
\text { with other } \\
\text { systems }\end{array}$ & $\begin{array}{l}\text { The main interaction is basically with the VBE information management system to have } \\
\text { access to the VBE members profile and competencies as well as access to collaboration } \\
\text { history. }\end{array}$ \\
\hline
\end{tabular}


Having into consideration the main requirements of the negotiation support environment as well as the identified mechanisms, Fig.2illustrates the strategic dependency model for the negotiation of a goal-oriented collaborative network (VO) where the dependences between actors and system modules are represented.

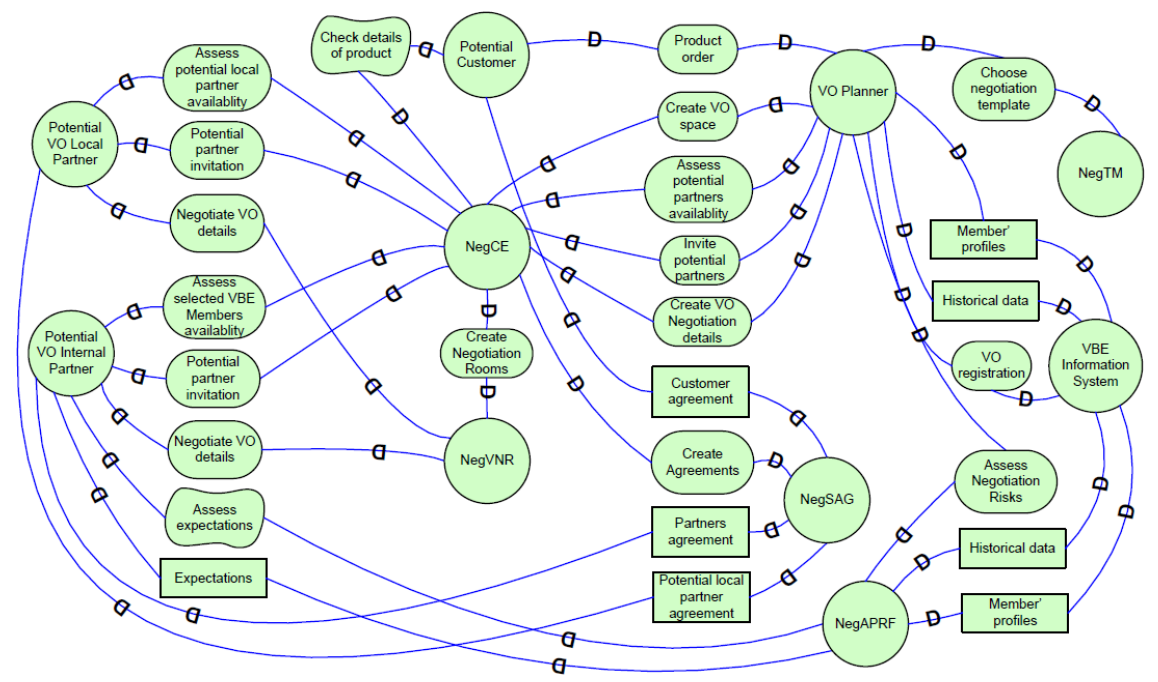

Fig. 2. Strategic dependency model for the negotiation support environment

Discussion of Results. As a first result, to support some of the previous concepts and basic functionalities, an Agreement Negotiation Wizard (WizAN) was designed and developed [5, 11]. The prototype aimed to assist the human users in their decision making process of consortia creation, structuring the negotiation process and making it traceable. The basic functionalities that were implemented were synchronism, negotiation editor, CSCW functionalities, privacy, and some other basic functionalities. Through interaction with some real VBE networks, the prototype was positively validated in a real scenario with a Swiss and a Chinese VBE supporting negotiations between partners from the two geographical areas [5].As a result, it is possible to draw some positive conclusions, namely in terms of preventing misunderstandings (particularly cultural) due to focused negotiation and the possibility to attach (electronic) documents. Moreover, a degree of authenticity is also guaranteed due to the existence of an eNotary service. Also, the system ensures the privacy of the information exchanged during negotiations, guaranteeing that partners have access only to authorized information. Therefore, by using such system, it is possible to reduce the negotiation time of the VO creation process, which increases the agility indicator.

Through the on-going $\mathrm{PhD}$ research and participation in European research projects, the topic of participants' expectation assessment and collaboration risk forecasting during a VO creation phase, gains more significance also for the agility indicator because it is possible to reduce the risks in collaboration and increase adaptation to unexpected events. So a first identification of risk drivers and sources is prepared and summarized in this paper. The test bed to assess the agility indicator in VO creation phase is provided by the GloNet project in a solar park context. 


\section{Conclusions and Further Work}

As it has been discussed for several years, the virtual organizations paradigm is of extreme importance for companies to survive in a competitive market. It is therefore vital to provide mechanisms to allow more dynamism in the process of consortia creation for VOs. If during the creation process the VO is aware of the potential risks that such collaboration might have during the operation phase, it will indeed be much simpler to overcome or even to avoid some execution/operation problems. Moreover, if the VO has its governing rules and principles as well as knowledge of the potential collaboration risks well defined in its collaboration agreement, then the chances of success will certainly increase. If there is an electronic negotiation support environment to help organizations to structure and conduct the entire negotiation process, then the VO creation process can become more agile.

This paper summarizes an on-going research work that tries to accomplish the above requirements. As some of the concepts and preliminary results have already been positively validated, it is now foreseen to achieve a more advanced environment that comprehends most of the described areas with the needed adaptations to support the aimed negotiation support for dynamic VOs with "smart" characteristics, such as: collaboration risks forecast, assessment of participants' expectations, traceability, etc.

A first identification of drivers and sources of those risks has already been achieved and presented in this paper. The emphasis of the current work is now on a taxonomy for potential risks in collaboration and how they are directly related to the potential participants expectations and competences. The validation process is then intended to consist in peer validation and supported by the EU project GloNet.

Acknowledgments. This work has been supported by the Collaborative Networks and Distributed Industrial Systems Research Group of Uninova and partly by the GloNet project (FP7 programme) funded by the European Commission.

\section{References}

1. Bititci, U., Turner, T., Mackay, D., Kearney, D., Parung, J., Walters, D.: Managing synergy in collaborative enterprises. Production Planning \& Control 18(6), 454-465 (2007)

2. Camarinha-Matos, L.M., Afsarmanesh, H.: Related Work on Reference Modeling for Collaborative Networks. In: Camarinha-Matos, L.M., Afsarmanesh, H. (eds.) Collaborative Networks: Reference Modeling, pp. 15-28. Springer (2008)

3. Husdal, J.: A Conceptual Framework for Risk and Vulnerability in Virtual Enterprise Networks. In: Managing Risk in Virtual Enterprise Networks: Implementing Supply Chain Principles, p. 1 (2010)

4. Camarinha-Matos, L.M., Afsarmanesh, H., Ollus, M.: ECOLEAD and CNO base concepts. In: Camarinha-Matos, L.M., Afsarmanesh, H., Ollus, M. (eds.) Methods and Tools for Collaborative Networked Organizations, pp. 3-32. Springer (2008)

5. Oliveira, A.I., Camarinha-Matos, L.M., Pouly, M.: Agreement negotiation support in virtual organisation creation-an illustrative case. Production Planning \& Control 21(2), $160-180(2010)$ 
6. Afsarmanesh, H., Camarinha-Matos, L.M., Ermilova, E.: VBE Reference Framework. In: Methods and Tools for Collaborative Networked Organizations, pp. 35-68. Springer (2008)

7. Atzori, L., Iera, A., Morabito, G.: The internet of things: A survey. Computer Networks 54(15), 2787-2805 (2010)

8. Giusto, D., Iera, A., Morabito, G., Atzori, L.: The Internet of Things: 20th Tyrrhenian Workshop on Digital Communications. Springer (2010)

9. Bucherer, E., Uckelmann, D.: Business Models for the Internet of Things. In: Architecting the Internet of Things, pp. 253-277. Springer (2011)

10. Camarinha, L.M., Oliveira, A.I., Sesana, M., Galeano, N., Demsar, D., Baldo, F., Jarimo, T.: A framework for computer-assisted creation of dynamic virtual organisations. International Journal of Production Research 47(17), 4661-4690 (2009)

11. Oliveira, A.I., Camarinha-Matos, L.M.: Agreement Negotiation Wizard. In: Camarinha-Matos, L.M., Afsarmanesh, H., Ollus, M. (eds.) Methods and Tools for Collaborative Networked Organizations, pp. 191-218. Springer (2008)

12. Picard, W., Rabelo, R.J.: Engagement in collaborative networks. Production Planning \& Control: The Management of Operations 21(2), 101-102 (2010)

13. Parung, J., Bititci, U.S.: A metric for collaborative networks. Business Process Management Journal 14(5), 654-674 (2008)

14. Child, J., Faulkner, D., Tallman, S.: Strategies of cooperation: Managing alliances, networks, and joint ventures. Oxford University Press, USA (2005)

15. Jüttner, U., Peck, H., Christopher, M.: Supply chain risk management: outlining an agenda for future research. International Journal of Logistics: Research and Applications 6(4), 197-210 (2003)

16. Harland, C., Brenchley, R., Walker, H.: Risk in supply networks. Journal of Purchasing and Supply Management 9(2), 51-62 (2003)

17. Turel, O., Yuan, Y.: User acceptance of Web-based negotiation support systems: The role of perceived intention of the negotiating partner to negotiate online. Group Decision and Negotiation 16(5), 451-468 (2007)

18. Strobel, M., Weinhardt, C.: The Montreal Taxonomy for Electronic Negotiations. Group Decision and Negotiation 12(2), 143-164 (2003)

19. Gimpel, H., Jennings, N.R., Kersten, G.E., Ockenfels, A., Weinhardt, C.: Negotiation, Auctions, and Market Engineering. LNBIP, vol. 2. Springer, Heidelberg (2006)

20. Rocha, A.P., Oliveira, E.: An Electronic Market Architecture for the Formation of Virtual Enterprises. In: Infrastructures for Virtual Enterprises - Networking Industrial Enterprises. Kluwer Academic Publishers, Boston (1999)

21. Jennings, N.R., Norman, T.J., Faratin, P., O'Brien, P., Odgers, B.: Autonomous Agents for Business Process Management. Journal of Applied Artificial Intelligence 14, 145-189 (2000)

22. Bartolini, C., Preist, C., Jennings, N.R.: A software framework for automated negotiation. In: Choren, R., Garcia, A., Lucena, C., Romanovsky, A. (eds.) SELMAS 2004. LNCS, vol. 3390, pp. 213-235. Springer, Heidelberg (2005)

23. Camarinha-Matos, L.M., Macedo, P., Ferrada, F., Oliveira, A.I.: Collaborative Business Scenarios in a Service-Enhanced Products Ecosystem. In: Camarinha-Matos, L.M., Xu, L., Afsarmanesh, H. (eds.) PRO-VE 2012. IFIP AICT, vol. 380, pp. 13-25. Springer, Heidelberg (2012) 